\title{
La colonización rural con inmigrantes en Argentina a mediados del siglo XX: Un efímero impulso desarrollista alentado por el CIME*
}

\author{
por \\ Emilio Redondo Carrero ${ }^{1}$ \\ Universidad de Castilla-La Mancha
}

La colonización rural con inmigrantes en Argentina suele considerarse un fenómeno circunscrito entre finales del siglo XIX y comienzos del XX. Las décadas posteriores de los cincuenta y los sesenta, por el contrario, son celebradas como la época de la industrialización. El objetivo de este artículo es determinar hasta qué punto aquella inmigración colonizadora estuvo presente en los planes del gobierno argentino a mediados de siglo, situar esos proyectos en un contexto internacional dominado por el fervor desarrollista, y analizar los resultados prácticos que, en tal sentido, produjo la cooperación con el Comité Intergubernamental para las Migraciones Europeas (CIME). Para ello, utilizaré sobre todo documentación primaria - tal como correspondencia oficial, informes y actas - procedente de la administración argentina y del mencionado Comité, además de recortes de prensa e información cuantitativa.

Palabras Clave: Argentina; siglo XX; desarrollismo; colonización rural; inmigración; CIME.

CÓmo CitAR eSTE ARTículo / CitATion: Redondo Carrero, Emilio, "La colonización rural con inmigrantes en Argentina a mediados del siglo XX: Un efímero impulso desarrollista alentado por el CIME”, Revista de Indias, LXXVII/271 (Madrid, 2017): 823-851. doi:10.3989/ revindias.2017.024

* El presente artículo ha sido elaborado en el marco del proyecto de investigación "Políticas migratorias en el Cono Sur: Un escenario de cambios legislativos que compromete diferentes escalas y actores, 1930-1979" (HAR2015-63689-R), financiado por el Ministerio de Economía y Competitividad.

1 Correo electrónico: emilio.redondo@me.com; ORCID iD: orcid.org/0000-0002-16728659. Este artículo está basado en parte de una tesis doctoral defendida en noviembre de 2016 en la Facultad de Letras de la Universidad de Castilla-La Mancha. 
La colonización agrícola y la inmigración europea fueron dos de los pilares en que se sustentaron las aspiraciones modernizadoras de la sociedad argentina desde el siglo XIX. Podría pensarse que, hacia finales de los años cincuenta del siglo XX, en un momento en que la industria avanzada era el paradigma del desarrollo y el epítome de la modernidad, la colonización del agro argentino había dejado de atraer la atención de la clase dirigente y que, en consecuencia, el encauzamiento de la inmigración hacia este particular no constituía ya una prioridad. Nada más lejos de la realidad, como bien advierte Alejandro Fernández:

El mito colonizador sobrevivió todavía en proyectos de los funcionarios de Perón (1946-55) y Frondizi (1958-62), con argumentos similares a los que eran usuales un siglo antes, aunque esos gobiernos priorizaban el desarrollo de la industria autóctona. La asociación entre inmigración y colonización agrícola fue por lo tanto muy duradera ${ }^{2}$.

El motivo de esta sólida pervivencia el autor lo halla, por un lado, en el éxito cosechado por los programas que, hacia finales del XIX, fueron llevados a la práctica en regiones como Santa Fe y el Alto Valle del Río Negro; por otro, en la progresiva desaparición de la ganadería como primera actividad exportadora en beneficio de la agricultura, acompañada del lógico incremento de la demanda de mano de obra en el campo. No obstante, Fernández apunta una tercera razón que resulta especialmente reveladora: la «esperanza pertinaz de que esa asociación entre inmigración y agricultura haría posible la conformación, en las zonas rurales del interior, de una sociedad diversificada y democrática» ${ }^{3}$. Puede intuirse, entonces, una cadena causal ideal en la que el desarrollo social del país acompañaría al desarrollo económico, el cual se apoyaría en una colonización rural efectiva que, a su vez, requeriría de una inmigración adecuada. Aunque no siempre generó perspectivas igual de optimistas, el binomio entre inmigración y colonización persistió así incólume hasta mediados de siglo, cuando se convertiría para los planes del gobierno en uno de los puntales del desarrollo económico y, en última instancia, social. Ahora bien, por cuanto sus fundamentos no fueron exactamente los mismos

2 Fernández, 2014: 14. Así lo consideran también Barbero y Cacopardo: «A pesar de todo no deja de ser sugestiva la persistencia de la idea de poblar el campo con inmigrantes, aún en la etapa en la que la producción agropecuaria había dejado de ser el motor del crecimiento económico. Podría atribuirse en parte a factores histórico-culturales que alimentaban el viejo mito colonizador del siglo pasado, pero podría también ligarse al hecho de que el sector rural seguía cumpliendo un papel clave en la actividad productiva y el único que generaba un saldo de divisas en el comercio exterior». Barbero y Cacopardo, 1991: 320.

3 Fernández, 2014: 14. 
que lo habían sustentado décadas atrás, el fenómeno de la colonización rural con inmigrantes en la Argentina de mediados del siglo XX ha de ser ubicado primero en el contexto del desarrollismo latinoamericano.

\section{LA AGRICULTURA Y LA INMIGRACIÓN EN EL DESARROLLISMO LATINOAMERICANO}

El concepto de desarrollo, según se concibe hoy en el ámbito de las ciencias sociales, alcanza su madurez de manera paralela al avance de la descolonización. Dos guerras mundiales en las que las potencias europeas trataron de destruirse mutuamente terminaron por demostrar que la pretendida superioridad occidental no era tal. Con el desmantelamiento de los imperios coloniales, la modernidad, hasta entonces tenida por una singularidad de las sociedades avanzadas de Europa y Estados Unidos, se convirtió de repente en una meta a la que todas las naciones del mundo podían aspirar. Para lograr este objetivo, políticos e intelectuales procedentes, en su mayoría, de los países avanzados se aplicaron en la tarea de diagnosticar y erradicar los obstáculos que mantenían a esas nuevas naciones ancladas en el subdesarrollo y les impedían alcanzar la etapa culminante de la modernidad. De manera muy resumida, esto es lo que se conocería como teoría del desarrollo.

En realidad, por buenas que fueran sus intenciones, este nuevo paradigma no dejaba de ser un constructo teórico con un marcado sesgo ideológico, por cuanto seguía situando a Europa y a Estados Unidos en la cumbre del progreso, como un ideal que el resto de sociedades debían imitar ${ }^{4}$. Además, al contrario de lo que sucede hoy día, por entonces el desarrollo se contemplaba exclusivamente en su dimensión económica ${ }^{5}$. El desarrollismo estaba estrechamente emparentado con el pensamiento económico neoclásico y su modelo de crecimiento «hacia fuera», cuyo objetivo principal era un saldo positivo en la balanza de pagos posibilitado, a su vez, por un incremento sostenido de las exportaciones. De esta manera, instituciones como el Fondo Monetario Internacional, creado en las postrimerías de la Segunda Guerra Mundial, prescribirían sus recetas a los países descolonizados con el fin primordial de mejorar su superávit comercial.

4 Dos Santos, 1999: 15.

5 Solo muchos años después el problema del desarrollo será abordado desde otros enfoques, como los derechos humanos y la protección del medio ambiente. Véase, por ejemplo, Sunkel, 1991. 
Por su parte, los países de América Latina, aunque habían dejado de ser colonias en el siglo XIX, en realidad nunca habían llegado a verse completamente libres de presiones e injerencias extranjeras. Así, por ejemplo, había sucedido con Argentina durante el desarrollo de la guerra, cuando los Aliados habían tratado por todos los medios de forzar al gobierno a abandonar su posición de neutralidad 6 . Esas injerencias eran, además, favorecidas por su débil situación económica, causada por la crisis del modelo agroexportador. En estas circunstancias, tanto Argentina como el resto de países del área, sintiéndose ahora identificados con los pueblos recién descolonizados, no dudaron en reclamar en la esfera política la independencia que ya tenían en el ámbito económico ${ }^{7}$. Surgió entonces en América Latina una variante del desarrollismo que, enfrentada a los principios esgrimidos desde Europa y Estados Unidos, intentó buscar vías alternativas hacia el progreso.

Este nuevo enfoque sobre la problemática del desarrollo en toda el área provino, especialmente, de la Comisión Económica para América Latina (CEPAL), creada en 1948 en el seno de las Naciones Unidas. Y sería su director, el argentino Raúl Prébisch, el principal ideólogo responsable de realizar una sólida crítica a la teoría neoclásica desde el estructuralismo. En su opinión, un modelo de crecimiento «hacia dentro», basado no tanto en el aumento de las exportaciones como en un potente proceso de industrialización, sería el «único medio» del que dispondrían los países de la periferia para «ir captando una parte del fruto del progreso técnico y elevando progresivamente el nivel de vida de las masas» ${ }^{8}$. Ahora bien, si la industrialización ocupaba una posición tan preponderante en el programa desarrollista, ¿en qué lugar quedaba la colonización rural?

Fernando Bastos de Ávila, en un denso estudio publicado a comienzos de los sesenta, afirmaba que para que América Latina, en su conjunto, superase la fase de subdesarrollo se precisaba de «todo un programa de progreso concentrado en esta trinidad: industrialización, desarrollo agrícola y progreso social» ${ }^{9}$. La cuestión agraria no podía quedar, por tanto, al margen de ningún plan gubernamental. «En un continente que se está desarrollando, como América Latina, en que la atención se polariza cada vez más hacia el sector indus-

6 Véase, por ejemplo, Quijada, 1994: 236. Senkman, 1985: 109.

7 Dos Santos, 1999: 13.

8 Prébisch, 1949: 6.

9 Bastos de Ávila, 1964: 126. Fernando Bastos de Ávila (1918-2010), sacerdote jesuita brasileño, fue un gran estudioso de la cuestión migratoria en el continente latinoamericano. Véase su biografía completa en la web de la Academia Brasileira de Letras: http://www.academia.org.br/academicos/fernando-bastos-de-avila-pe/biografia. 
trial, sería un error de consecuencias serias perder de vista la agricultura», reivindicaba el autor ${ }^{10}$. Y añadía:

La industrialización [...] es un imperativo, por lo que se refiere al desarrollo económico de América Latina. Ahora bien, no debemos olvidar otro elemento no menos vital, como es el desarrollo agrícola. Precisamente la exportación de productos agrícolas es, y seguirá siendo aún por mucho tiempo, una fuente de equilibrio en la balanza de pagos. Es también la agricultura la que nos proporciona las divisas necesarias para la adquisición del equipo industrial en los mercados internacionales. Argentina y Uruguay sin su carne y trigo, y Brasil y Colombia sin su café, no hubieran podido entregarse a la creación de industrias pesadas y de transformación ${ }^{11}$.

A primera vista, parece que lo anterior contradice las tesis desarrollistas de Raúl Prébisch y la CEPAL, por cuanto estas preconizaban el fin del modelo agroexportador y fomentaban en todo el continente una industrialización sustitutiva de importaciones. Y es cierto que esta fue una de las principales críticas que se dirigieron hacia el organismo, llegando algunos teóricos incluso a atribuir a Prébisch cierta animadversión por la agricultura. Sin embargo, preguntado este al respecto en una entrevista, el argentino respondió que tales acusaciones no eran sino «pamplinas»:

Decía que si no hay industrialización en los países en desarrollo, en la periferia, y si hay progreso técnico en la agricultura, la relación de precios de intercambio tenderá al deterioro. La única forma de frenar esa tendencia es la industrialización. [...] Presenté una tesis como argumento a favor de la industrialización. ¿En contra de la agricultura? ¿Cómo podría? ¿Un hombre nacido y criado en la Argentina, que reconocía que el alto nivel de vida de su país a comienzos de siglo se debía a la agricultura? [...] La agricultura puede ser fuente de riqueza ${ }^{12}$.

Por lo que respecta a Argentina, el gobierno no encaró de manera enérgica el supuesto problema del subdesarrollo hasta la llegada de Arturo Frondizi a la presidencia. El esfuerzo previo de Juan Domingo Perón por alcanzar las metas de la modernidad mediante sus planes quinquenales pronto había mostrado síntomas de agotamiento. Y tras su derrocamiento, los gobiernos de la Revolución Libertadora no mostraron gran preocupación por el progreso de la economía ${ }^{13}$. De este modo, puede decirse que no es hasta 1958 cuando una

10 Bastos de Ávila, 1964: 165.

11 Ibidem: 143-144.

12 Pollock, Kerner y Love, 2001: 17.

13 Cabe añadir que en 1956, bajo el gobierno del general Pedro E. Aramburu, fue creado el Instituto Nacional de Tecnología Agropecuaria (INTA). Sin embargo, según Celia Szuster- 
política desarrollista inspirada en los principios de la CEPAL hace su irrupción en el país. Cabe precisar que ni Frondizi ni su máximo colaborador, Rogelio Frigerio, admitirían jamás la influencia cepalina en el diseño de su programa desarrollista, y que, de hecho, este presentaría algunas diferencias respecto al modelo postulado por Prébisch - entre ellas, la importancia concedida al capital extranjero en el proceso industrializador-. No obstante, a pesar del aparente rechazo de las tesis cepalinas, García Bossio sugiere que «los diagnósticos de Frigerio sobre las causas estructurales del atraso argentino y sobre su carácter subdesarrollado y periférico estaban netamente emparentados con aquellos principios» ${ }^{14}$.

Puede afirmarse, entonces, que Frondizi y Frigerio siguieron los preceptos de la CEPAL cuando, en su intento de corregir y reforzar las reformas iniciadas por Perón, potenciaron la siderurgia y otras industrias de base. Sin embargo, también hay que advertir que otro aspecto en el que ambos programas se distanciaron, aparte de la inversión extranjera, fue la agricultura, a la que el desarrollismo argentino no dejó de situar en un lugar preeminente. Aun cuando ha de interpretarse también como un signo de cierta inquina personal, es significativo que Frondizi y Frigerio aplicaran despectivamente a Prébisch el calificativo de «cripto industrialista» por su excesivo afán industrializador ${ }^{15}$. Más allá de invectivas poco fundadas, como ha estudiado Silvia Lázzaro, «en la concepción de Frigerio no existe una cuestión agraria separada de los problemas genéricos de la economía nacional, en tanto el obstáculo es uno solo, tanto para el agro como para la industria: el subdesarrollo. [...] Sobre la base del anterior argumento queda abiertamente planteada la absoluta interdependencia del desarrollo del agro, la minería y la industria; y la influencia recíproca de un sector de la economía sobre los demás» ${ }^{16}$.

Por otro lado, la hostilidad del gobierno hacia el ideario marxista le hizo descartar la mala distribución de la tierra como origen del atraso agrario que padecía Argentina. Al contrario, Frondizi y Frigerio estaban convencidos de que la falta de capital y de insumos tecnológicos eran la causa principal. La política agraria debía centrarse en la obtención de ambos para conseguir un incremento de la productividad. Lázzaro, al igual que otros autores, ha analizado detalladamente las medidas concretas impulsadas desde el gobierno con

man, este presidente no introdujo ninguna modificación de importancia respecto a la política económica llevada a cabo durante el peronismo. Szusterman, 1993: 93.

14 García Bossio, 2013: 24. Véase también Cerra, 2010: 1666-1680.

15 Qué!, 16 de octubre de 1956: 4, ap. García Bossio, 2013: 16.

16 Lázzaro, 2012: 137-138. 
este fin, así como los resultados obtenidos ${ }^{17}$. Sin embargo, la mayoría de esos análisis suelen olvidar un factor que fue fundamental para el desarrollismo agrario argentino en la búsqueda de ese progreso tecnológico: la inmigración extranjera.

El impulso desarrollista, en todas sus variantes, no requería solo de capital financiero, sino también de conocimientos técnicos. Con la expresión «potencial humano», el propio Prébisch se refería usualmente al factor de producción compuesto por toda aquella mano de obra cualificada necesaria para llevar a cabo cualquier programa de desarrollo económico. Dado que se consideraba que los países de América Latina carecían de este recurso, debían procurárselo por cualquiera de los medios a su disposición. El primero de ellos consistía en la formación de esos recursos de manera autóctona, para lo cual era necesario implantar una educación de calidad en cada país ${ }^{18}$. La otra vía, mucho más inmediata, era la importación de trabajadores cualificados desde los países en que eran más abundantes, europeos sobre todo. La política migratoria de un Estado con aspiraciones desarrollistas debía enfocarse primordialmente a la adquisición de estos recursos. En este último sentido, Bastos de Ávila consideraba que «un programa de fomento a la inmigración solo tendrá valor y eficacia dentro de un programa general de desarrollo económico»:

La inmigración a América Latina solo podrá asumir proporciones importantes cuando sus países, acelerando el ritmo de su progreso, ofrezcan a los inmigrantes condiciones de vida capaces de competir con las de los grandes países contemporáneos de inmigración. Una vez provocado este movimiento, los inmigrantes vendrán en número más elevado cada año, aliviando de este modo la presión demográfica de los países superpoblados. Y vendrán a América, como van a los Estados Unidos, Canadá o Australia ${ }^{19}$.

El proyecto desarrollista, por tanto, requería de la «indispensable contribución» de la inmigración ${ }^{20}$. Y, por supuesto, esto abarcaba también al sector agrario, donde el proceso de tecnificación necesario para incrementar la productividad exigía la captación del conocimiento y la experiencia de agricultores y peritos formados en Europa. Volviendo al caso argentino, así reconocía el propio Frondizi, al comienzo de su mandato, la importancia de invertir en «potencial humano» destinado también al campo:

\footnotetext{
17 De esta autora, véase también Lázzaro, 2008: 85-106.

18 Echavarría, 1967.

19 Bastos de Ávila, 1964: 121.

20 Ibidem: 125.
} 
La Argentina va a necesitar, sobre todo, técnicos y operarios fabriles, pero ello no excluye que la activación de las extracciones, la mecanización rural, que acompañarán a nuestros esfuerzos, no demanden, a su vez, brazos experimentados y familias deseosas de aportar sus conocimientos a nuestro propio país ${ }^{21}$.

De este modo, la colonización con inmigrantes revivió en la Argentina de finales de los cincuenta, adaptando lo que era una práctica secular a las exigencias del contexto desarrollista. Su finalidad primordial, ahora, no sería tanto el poblamiento en sí como la introducción de mejoras técnicas destinadas a mejorar la productividad, un propósito para el que la colonización con nacionales no servía:

Un método de integración de la agricultura en el ritmo de progreso general es la colonización. Y es un error pensar en la colonización extranjera y nacional como realidades rivales. Se complementan. El colono nacional, por su adaptación al medio y su fuerza de penetración es el elemento básico para la obra de población y ocupación de las tierras. El colono extranjero, con más conocimiento de las técnicas, es un factor de elevación de los niveles económicos y sociales del grupo ${ }^{22}$.

\section{LA PARTICIPACIÓN DEL CIME EN LA COLONIZACIÓN RURAL}

En los proyectos colonizadores de mediados de siglo XX en América Latina tuvo un papel muy destacado el Comité Intergubernamental para las Migraciones Europeas (CIME), un organismo multilateral creado en 1951 para gestionar los traslados de migrantes y refugiados hacia otros continentes desde una Europa superpoblada como consecuencia de los desastres causados por la Segunda Guerra Mundial. Los países fundadores ya tuvieron en cuenta, en el momento de su constitución, que el problema del desarrollo económico y la inmigración estaban estrechamente relacionados ${ }^{23}$. Sin embargo, la actividad inicial del organismo apenas contempló las condiciones de dependencia

21 "Declaraciones de Arturo Frondizi al periódico $\mathrm{Ya}$ de Madrid, reproducidas en El $\mathrm{Na}$ cional de 1. ' de diciembre de 1958", Revista de la Dirección Nacional de Migraciones (DNM), I/1 (Buenos Aires, 1959): 37.

22 Bastos de Ávila, 1964: 165. El autor afirma en otro lugar: «La inmigración agrícola para América Latina, sin embargo, hoy solo se puede hacer prácticamente bajo la forma de colonias. Y esto, porque la inmigración colonizadora es la que mejor conviene a los intereses del inmigrante rural y más promueve los intereses de la comunidad agrícola en que se va a integrar». Ibidem: 54.

23 Proyecto de resolución constitutiva de un Comité Intergubernamental Provisional para los Movimientos Migratorios de Europa, Bruselas, 24 de noviembre de 1951, Biblioteca de la Organización Internacional para las Migraciones, Ginebra (BOIM), MCB/9. 
que, según la perspectiva estructuralista, lastraban el desarrollo de los países latinoamericanos. Al contrario, considerada únicamente su capacidad para recibir el excedente de población europeo, países como Argentina o Venezuela fueron clasificados en el mismo grupo que Canadá, Australia o los Estados Unidos. Durante la conferencia inaugural de Bruselas, en 1951, varios delegados emitieron la queja de que el organismo desatendía las necesidades de los países de inmigración ${ }^{24}$. A pesar de que se habló de la posibilidad de que aquellos se beneficiaran del aporte inmigratorio para su desarrollo económico, el CIME no puso mayor empeño al respecto.

No obstante, al avanzar la década de los cincuenta, se hizo más patente el malestar de los países latinoamericanos con el trato recibido del organismo. Poco a poco conscientes de su posición periférica en el sistema internacional, manifestaron de manera cada vez más explícita su descontento con la composición del flujo inmigratorio recibido, caracterizado por el predominio de mujeres y niños. La reagrupación familiar podía cumplir una función humanitaria muy loable, pero no contribuía a sus necesidades de desarrollo, solían argumentar. De tal modo, estos gobiernos incrementaron su presión sobre el Comité con el fin de ver realizada una verdadera corriente inmigratoria de profesionales cualificados. En estas coordenadas se sitúa, por ejemplo, la siguiente alocución del delegado venezolano durante una reunión del Consejo del CIME en 1955:

Creo [...] en la necesidad de insistir en un reforzamiento de la contribución del CIME a los servicios de migración y, muy especialmente, en los extremos encaminados a lograr un mayor perfeccionamiento de la formación profesional. [...] Cuando se habla de los países de América se los llama, en el orden económico y con gran exactitud, países poco desarrollados (aunque yo preferiría que se los llamase países en proceso de desarrollo). Aparte de la calificación, y sabiendo perfectamente que esa deficiencia de desarrollo es debida a múltiples causas, mi gobierno cree que una de las maneras de subsanarla es mediante un desarrollo económico progresivo, un desarrollo industrial progresivo, condicionado, entre otros factores, fundamentalmente por la posibilidad que se deriva de una entrada de elementos de formación profesional un tanto acabada ${ }^{25}$.

Si no quería alentar desafecciones, el CIME debía satisfacer las demandas de sus miembros latinoamericanos. No obstante, en el viraje que finalmente

24 Informe sobre la Conferencia General de Migraciones de Bruselas, celebrada del 26 de noviembre de 1951 al 5 de diciembre de 1951, Ginebra, 25 de febrero de 1952, BOIM, $\mathrm{MCB} / 12: 7-8$.

25 Acta taquigráfica de la $14 .{ }^{a}$ Sesión (II Reunión), 23 de mayo de 1955, BOIM, MC/C/ PV/14/Rev.1: 55. 
daría el Comité hacia unas políticas más centradas en las necesidades de estos países había también otra razón de fondo: la agudización de la Guerra Fría. Al fin y al cabo, el CIME había sido creado a iniciativa estadounidense como un organismo al servicio de la comunidad occidental, como un complemento del Plan Marshall, para alejar a los países europeos de la tentación soviética ${ }^{26}$. Pero la rápida recuperación europea y el triunfo de la Revolución cubana en 1959 hicieron cambiar el centro de gravedad de la geopolítica mundial, de tal modo que el gobierno de los Estados Unidos, ante el temor a la propagación del comunismo por el continente americano, impulsó diversos programas de ayuda destinados a paliar el malestar social de sus vecinos del sur ${ }^{27}$. Hay que tener en cuenta, además, que si había un sector de la población más propenso a la adopción del ideario marxista, este era el campesinado, cuyas condiciones de vida rayaban la pobreza absoluta. Estas circunstancias convirtieron a la cuestión agraria, por encima aun de la industrialización, en el núcleo de los planes de desarrollo del gobierno estadounidense, que fomentó en toda el área latinoamericana el reparto «no revolucionario» de tierras con el fin de detener el avance del comunismo ${ }^{28}$. Es desde esta perspectiva que también han de ser contemplados los proyectos de colonización rural impulsados por el CIME.

Ya fuese por las presiones directas de los países latinoamericanos, por la sumisión a los designios de la política exterior estadounidense, o por la simple necesidad de centrarse en nuevos objetivos una vez desaparecido el problema de la superpoblación europea, hacia finales de la década el CIME terminó implicándose de lleno en la cuestión del desarrollo. Y, dentro de este ámbito, como se acaba de referir, concedió especial importancia al nexo entre inmigración y colonización, como constataría un informe realizado años después:

El desarrollo es consecuencia de una combinación de recursos naturales, mano de obra y capital. En los países de inmigración, el recurso nacional que ofrecía la posibilidad evidente de un mejor aprovechamiento era la tierra — desarrollo agrícola- y uno de los métodos más adecuados de conseguirlo, con la importación de mano de obra calificada, era la creación de colonias agrícolas con la participación de inmigrantes. Por eso, el CIME empezó a establecer dichas colonias agrícolas y a ejecutar otros proyectos conexos ${ }^{29}$.

26 Redondo Carrero, 2017: 50-65.

27 Ibidem: 461-479.

28 De la Peña, 1997: 215.

29 "Esquema general de las actividades del CIME", Primer Curso Latinoamericano sobre Emigración, II, Ginebra, BOIM, septiembre de 1963: 2-3. 
En realidad, la colonización había sido objeto de discusión desde las fases más tempranas del organismo. Ya en junio de 1952, durante la tercera reunión del Comité, se aprobó la Resolución n. ${ }^{\circ} 24$ (III), por la que se exigía al director la adopción de medidas encaminadas a promocionar el movimiento migratorio desde Europa hacia los países de ultramar con fines colonizadores. Esta petición tuvo como resultado un informe presentado por el director solo unos meses después, durante la cuarta reunión, en el que se declaraba que «los proyectos de colonización agrícola constituían una de las mejores maneras de abrir nuevas posibilidades de inmigración» y se mencionaban, a modo de ejemplo, aquellos que ya habían sido llevados a cabo exitosamente en algunos países latinoamericanos ${ }^{30}$. En esa misma reunión, celebrada en octubre de 1952, se aprobó también la Resolución n. ${ }^{\circ} 36$ (IV), según la cual se favorecería la formulación de planes de colonización de los gobiernos miembros que desearan incrementar el número de inmigrantes recibidos por sus países. Y, un año más tarde, fue aprobada la Resolución n. ${ }^{\circ} 65$ (VI), la primera que explícitamente aludía en su título a la colonización agrícola y que sentaba ya unas bases concretas de actuación ${ }^{31}$. Tras esta última, siguieron muchas otras resoluciones que confirmaron el cada vez mayor compromiso del CIME para con los programas de colonización de los países inmigratorios, especialmente en América Latina, hasta llegar a la Resolución n. ${ }^{\circ} 243$ (XV), que, aprobada en el año 1961, vendría a suponer en este sentido un punto de inflexión en la actividad Comité32.

Ahora bien, una cosa era advertir la importancia clave de la colonización rural en los países de inmigración y otra distinta, más compleja, era trazar un plan de actuación concreto, adecuado a las circunstancias del momento, y llevarlo a cabo. Lo primero que para ello requería el CIME, antes de la adopción de medidas específicas, era algún tipo de argumentación que le facultara para intervenir, junto a los respectivos gobiernos, en los procesos de ocupación del agro de los distintos países. Desde el momento de la constitución de las repúblicas latinoamericanas, y no obstante la existencia de políticas estatales, la colonización había discurrido en muchos casos por cauces espontáneos. Hacia mediados del siglo XX, la menor predisposición popular hacia la misma suponía, por un lado, mayores posibilidades de control por parte de

30 Informe sobre colonización agrícola presentado por el director, Venecia, 12 de octubre de 1953, BOIM, MC/31.

31 Resolución $n .^{\circ} 65$ (VI), relativa a la colonización agrícola, ap. Proyecto de informe sobre la sexta reunión del CIME, Ginebra, 6 de enero de 1954, BOIM, MC/57.

32 Resolución $n .^{\circ}$ 243, (XV), sobre actividades futuras del Comité, 25 de octubre de 1961, BOIM, MC/510/Rev.1. Véase también Redondo Carrero, 2017: 476. 
los gobiernos, pero, por otro lado, también una mayor necesidad de intensificar ese control para alcanzar los objetivos propuestos. Resultaba esencial, entonces, diferenciar la colonización espontánea de la dirigida y acentuar los beneficios de esta última, para justificar de este modo el intervencionismo estatal y del propio Comité. Y eso es precisamente lo que se hacía en un documento informativo sobre la colonización agrícola en el año 1956:

Desde los tiempos primitivos, la inmigración colonizadora fue en gran medida de carácter espontáneo, conservando esta característica durante todo el siglo XIX. [...] Desde el final de la segunda guerra mundial ha habido muy pocas colonizaciones espontáneas en el campo, y no es difícil encontrar los motivos. En primer término, ya no se pueden conseguir tierras baratas; y se ha comprobado que las personas deseosas de emigrar y que poseen experiencia agrícola se muestran más reacias a trasladarse a ultramar, a no ser que puedan empezar a trabajar en su propia tierra o si tienen una posibilidad concreta de adquirir tierra propia dentro de un plazo razonable. $[\ldots]$

Es improbable que el tipo de hombre que puede ser un buen colono acepte un trabajo como peón asalariado en competencia con la mal pagada mano de obra local. En general, es la colonización agrícola organizada la que, desde un principio, facilita tierra al inmigrante y la que ofrece probabilidades de atraer a los pequeños agricultores o a los trabajadores agrícolas calificados de Europa. [...] No es posible que el éxito sonría a una colonia agrícola, por muy trabajadores y voluntariosos que sean los colonos, si no se hallan respaldados por un capital suficiente y el mínimo de conocimientos administrativos. Las técnicas agrícolas modernas requieren desembolsos de capital considerables para edificios agrícolas, tractores y otras máquinas, fertilizantes, ganado de buena raza, semillas seleccionadas, etc. [...]

Los inmigrantes están cada vez menos dispuestos a confrontar las dificultades de poner en cultivo nuevas tierras sin que existan el apoyo y la preparación adecuados. Este contraste entre la actitud del emigrante del siglo XX y de su predecesor del siglo XIX, como lo expresa el Sr. Colin Clark, «no se debe a un cambio profundo de actitud ni a la pérdida de arrojo de la generación actual. Es consecuencia principalmente del hecho de que las condiciones de vida en una población industrial - la otra solución posible para los colonizadores - eran mucho más difíciles y menos atractivas en el siglo XIX que hoy en día». Por consiguiente, es necesario organizar la colonización agrícola no solo desde el punto de vista técnico y administrativo, sino también para lograr que los colonos estén satisfechos del modo de vida que se les ofrece y estén dispuestos a permanecer en el campo ${ }^{33}$.

Una vez justificada de manera convincente la necesidad de una colonización organizada, había que aclarar en qué iba a consistir concretamente la participación del CIME en los proyectos estatales, más allá de su quehacer en el traslado de migrantes. Al comienzo, «se estimó que el Comité no debía emplear sus fondos en inversiones de este tipo ni asumir la responsabilidad

33 Documento informativo sobre colonización agrícola, 1956, BOIM, MC/INF/34. 
directa de los proyectos de colonización agrícola, sino que debería más bien actuar como agente catalizador, poniéndose a disposición de los gobiernos que lo solicitasen para ayudarles en la elaboración de planes y para su ulterior presentación a las instituciones financieras internacionales» ${ }^{34}$. Más adelante esta postura se fue matizando. La creciente demanda por parte de los países latinoamericanos de una mayor implicación del CIME en los proyectos de colonización supuso la firma de las resoluciones arriba mencionadas y el ensayo de fórmulas que iban más allá del simple asesoramiento. A la altura del año 1961, el procedimiento a seguir constaba ya, a grandes rasgos, de los siguientes pasos: (1) cuando lo pedía un gobierno, un experto del CIME efectuaba una encuesta preliminar para conocer la posibilidad de emprender un proyecto determinado y, si tal posibilidad existía, determinar los medios y los servicios técnicos suplementarios que se requerían para elaborarlo; (2) si el gobierno miembro decidía ir más allá y facilitar esos medios y servicios, el CIME encargaba a peritos agrícolas el asesoramiento en la elaboración detallada del proyecto; (3) si el gobierno resolvía finalmente acometer el proyecto, debía lanzarse a la búsqueda de los fondos necesarios para ello, acudiendo si era necesario a las instituciones financieras competentes; (4) por último, una vez se disponía de los recursos para iniciar el proyecto, el CIME colaboraba en la ejecución del proyecto hasta donde estimase necesario, lo que en muchos casos implicaba la destinación de fondos ${ }^{35}$.

\section{Resultados de la colonización del CIME en Argentina}

En la práctica, los resultados de la participación del CIME en los proyectos de colonización fueron más discutibles. En lo concerniente a Argentina, según las cifras de las Dirección Nacional de Migraciones, la inmigración de agricultores y otros trabajadores con profesiones relacionadas con el campo durante la presidencia de Frondizi supuso un tercio del total de la inmigración recibida por el país durante esos años. A su vez, solo la mitad de ese contingente llegó por intermedio del Comité, repartido entre sus programas de mano de obra y el de reagrupación familiar.

En cuanto a los asentamientos, propiamente dichos, el Comité venía cooperando desde muy temprano con el gobierno argentino en varios proyectos,

34 Informe sobre colonización agrícola presentado por el director, Venecia, 12 de octubre de 1953, BOIM, MC/31.

35 Algunas consideraciones sobre la política y los programas para el año 1962, 8 de mayo de 1961, BOIM, MC/462. 
Gráfica 1: Inmigrantes agricultores llegados a Argentina vs. total INMIGRACIÓN (1958-1962)

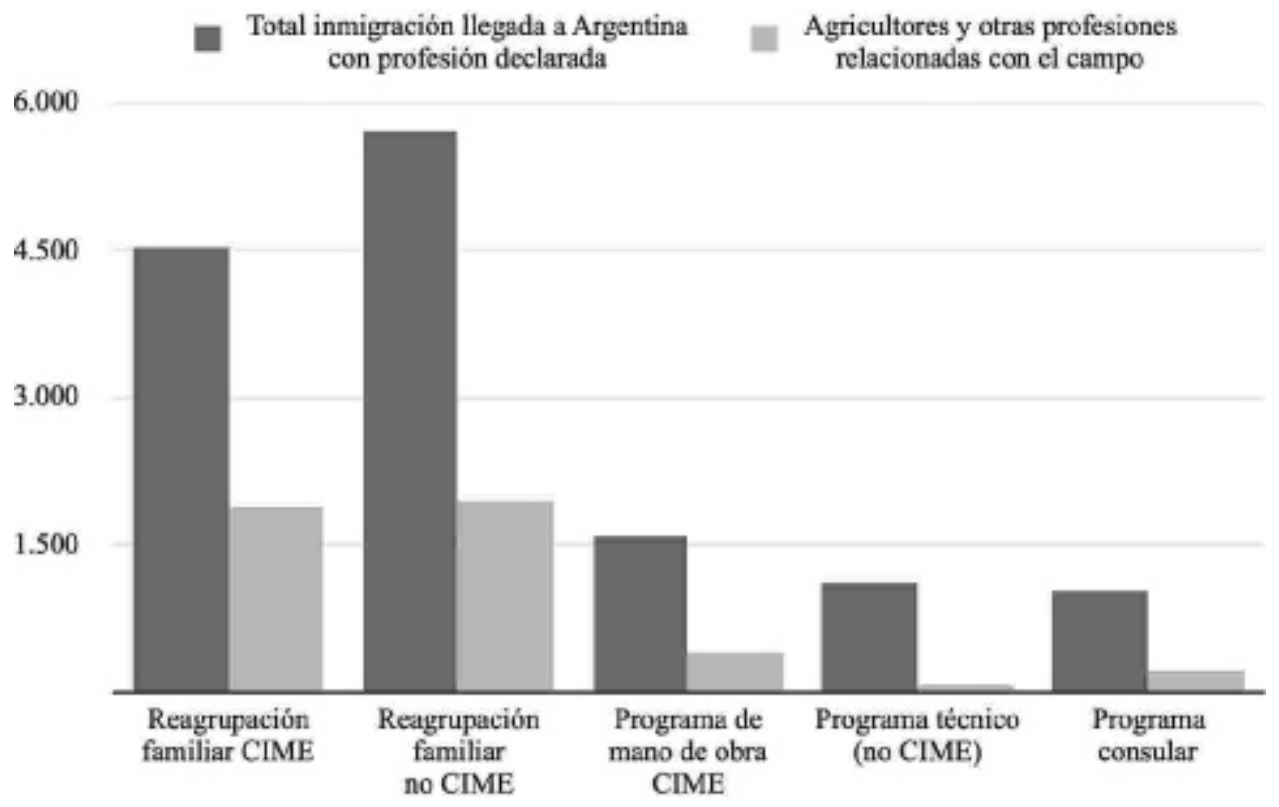

Fuente: Elaboración propia. Revista de la DNM, varios años, ADNM.

como los de la colonia Diecisiete de Octubre, en Florencio Varela, o el de una granja escuela en Santa Catalina, cerca de Llavallol — donde en el momento de la ratificación del acuerdo de adhesión por el Congreso argentino, en 1953, ya existían veinte colonos inmigrantes egresados - ${ }^{36}$. Pronto acordaron también el gobierno y el Comité la creación de sendos centros de formación profesional para inmigrantes rurales en las colonias de Florencio Varela y Melchor Romero, en las que éstos, tras un período de aprendizaje de seis meses, serían colocados como aparceros o trabajadores agrícolas. A los que hubieran demostrado mejores aptitudes, además, se les concedería en propiedad una granja especialmente dispuesta con tierra, vivienda, agua potable, cercados y un préstamo de capital para la explotación. Hacia mediados de

36 "Aprobación de la Constitución del CIME (Orden del día número 28)", Diario de Sesiones de la Cámara de Senadores, I (11 de agosto de 1954): 478, Biblioteca del Congreso de la Nación, Buenos Aires (BCN). 
1956, veintiséis familias inmigrantes habían sido ya trasladadas por el Comité a estas granjas, donde se dedicaban principalmente al cultivo de hortalizas ${ }^{37}$.

Tras estos éxitos iniciales, el gobierno trató de llevar a cabo otros proyectos en colaboración con el Comité, de tal modo que al año siguiente, en 1957, Argentina se había convertido en el país en cuyo plan general de colonización el CIME intervenía en un mayor grado. Entre los nuevos proyectos formulados, se encontraban los siguientes: una modificación de los planes primitivos en Melchor Romero, para permitir el asentamiento de más familias a lo largo de 700 hectáreas; la instalación de otras 150 familias en Valle Azul a lo largo de 3.000 hectáreas de regadío; la ampliación de un centro de acogida de inmigrantes ya existente en Tres Arroyos; la creación de un centro de inmigrantes en Laguna de los Padres - siguiendo un proyecto previamente formulado por el Banco de la Nación-; el acondicionamiento de 25.000 hectáreas en Viedma, en Río Negro, para su cultivo intensivo; y la adecuación, asimismo, de 15.000 hectáreas de tierras fiscales en la provincia de Corrientes para su cultivo extensivo ${ }^{38}$.

Pero las metas a las que aspiraba la colaboración entre el gobierno y el CIME resultaron ser demasiado ambiciosas. A pesar de aquellos primeros avances, la ejecución de los nuevos proyectos fue más problemática: tras ser modificados repetidas veces, algunos de ellos se descartaron, otros fracasaron al poco tiempo de ponerse en marcha, y solo unos pocos alcanzaron parcialmente su consecución. Cuando en los años siguientes el CIME comenzó a reorganizar sus actividades con el fin de adaptarse a la nueva situación internacional, los principales proyectos de colonización aún vigentes y en estudio fueron clasificados, junto a otros proyectos relativos a servicios distintos del transporte, bajo la denominación de «proyectos piloto», pasando a formar parte de una breve lista en la que el número asignado venía a indicar su nivel de prioridad.

Durante una reunión del Comité celebrada en febrero de 1958, se lanzó la propuesta de que los fondos remanentes de 1957 se utilizaran para «financiar proyectos piloto encaminados a aumentar la capacidad de absorción de los países receptores de inmigrantes ${ }^{39}$. Aceptada la propuesta, se decidió empezar por los primeros cuatro proyectos de la lista, cuyo coste total se estimaba

37 Informe del director sobre colonización agrícola, 30 de agosto de 1956, BOIM, $\mathrm{MC} / 203$.

38 Informe del director sobre las actividades desarrolladas desde la V Reunión, 20 de marzo de 1957, BOIM, MC/225.

39 Proyectos piloto destinados a aumentar la capacidad de absorción de los países de inmigración, 9 de mayo de 1958, BOIM, MC/287. 


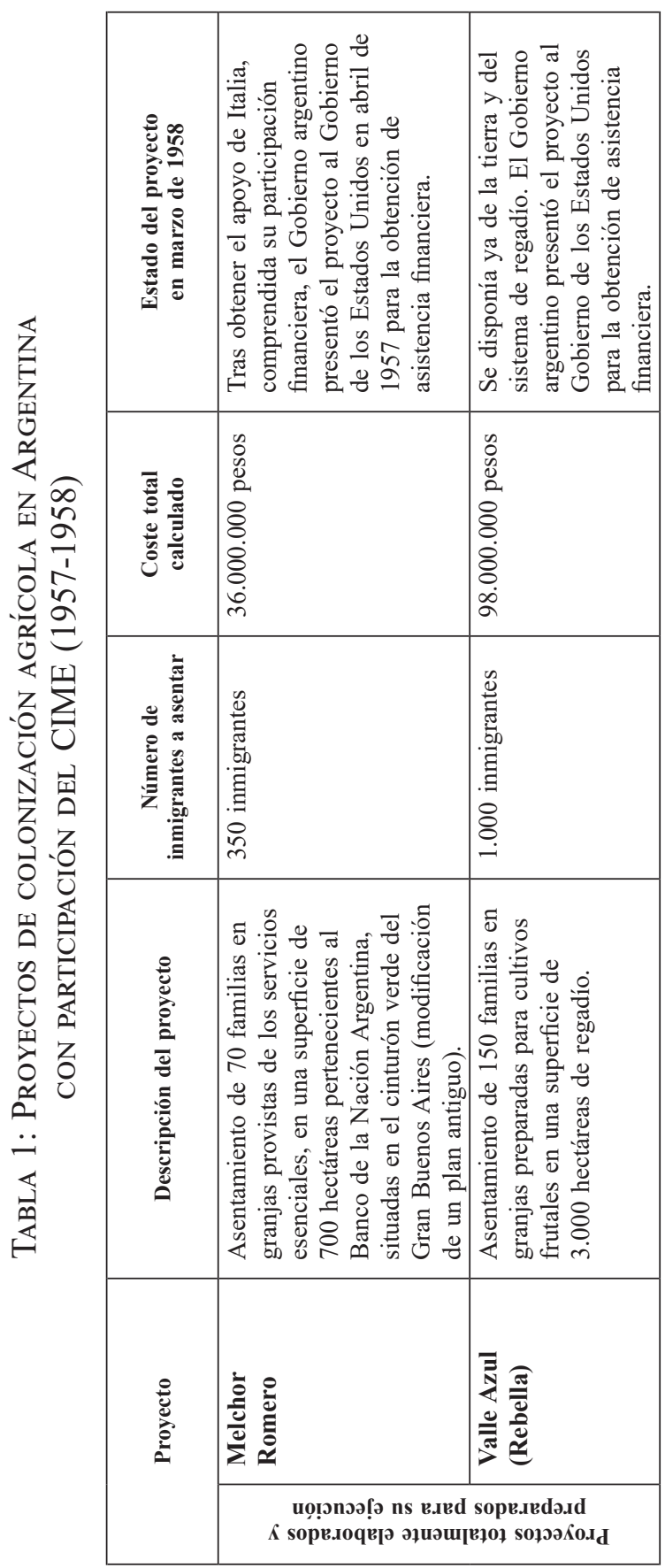




\begin{tabular}{|c|c|c|c|c|}
\hline 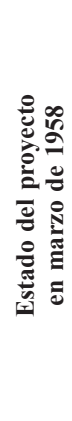 & 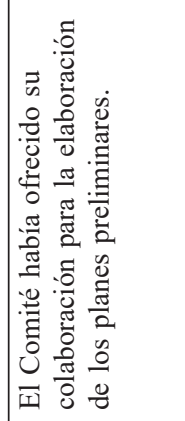 & 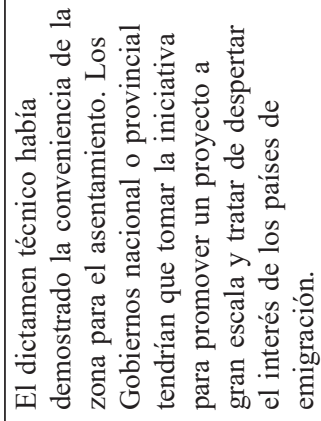 & 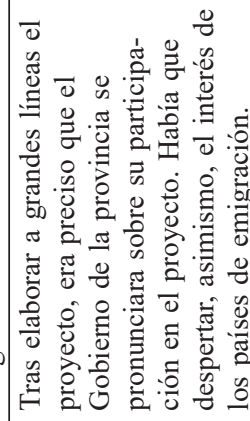 & 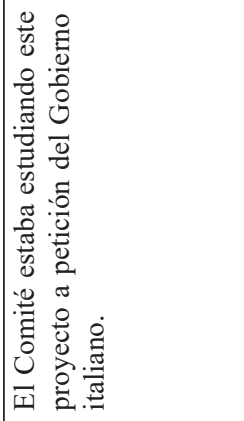 \\
\hline 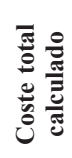 & & & & \\
\hline 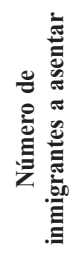 & & & & \\
\hline 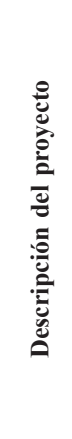 & 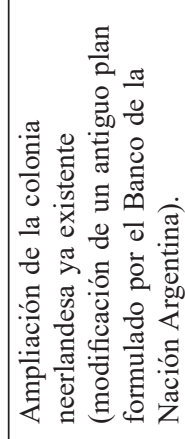 & 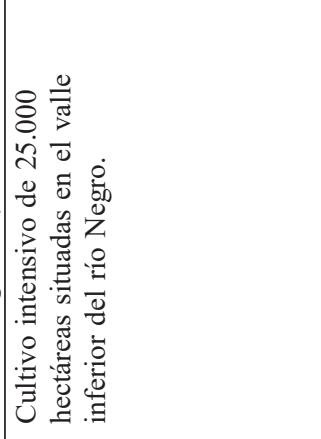 & 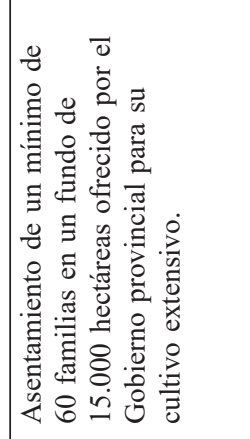 & 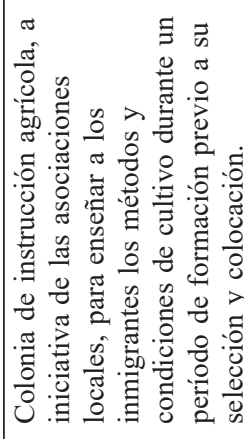 \\
\hline 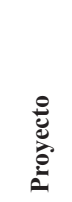 & 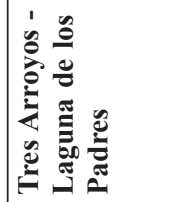 & 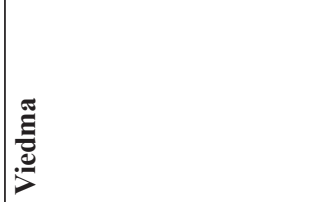 & 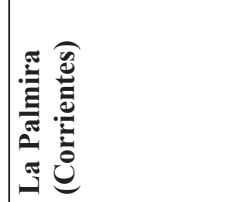 & 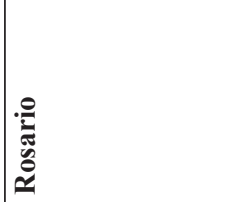 \\
\hline & \multicolumn{4}{|c|}{ 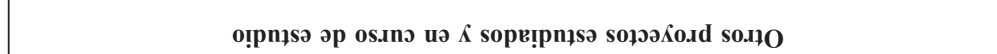 } \\
\hline
\end{tabular}

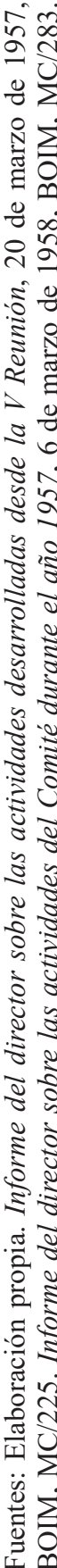


Mapa 1: Proyectos de colonización agrícola en Argentina
CON ParticipaCión del CIME (1957-1958)

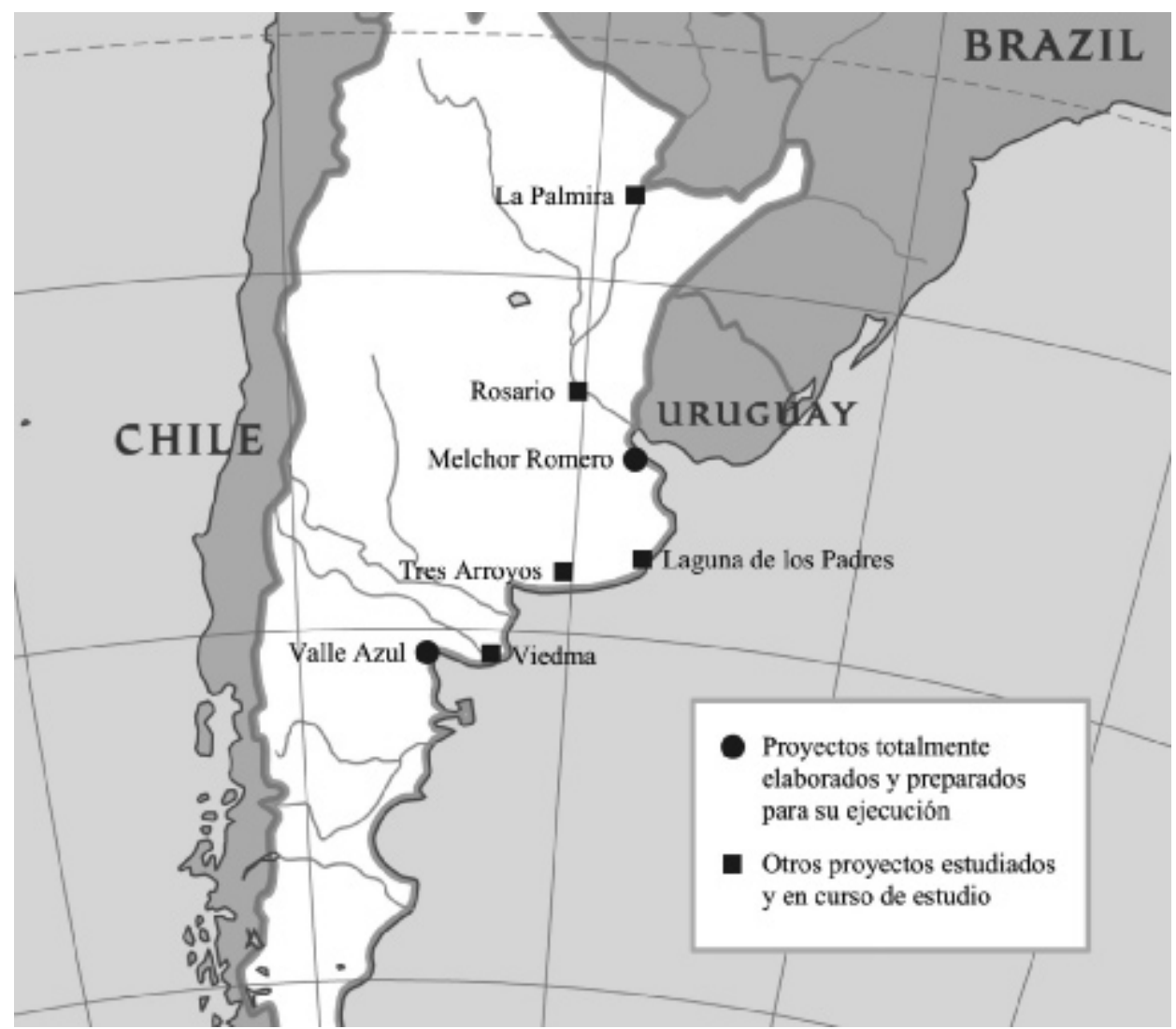

Fuentes: Elaboración propia. Véase la tabla anterior.

en 1.330.000 dólares, de los cuales el CIME aportaría 650.000 dólares. De esos cuatro proyectos, el tercero era el que concernía a la Argentina, al contemplar la creación en Santa Fe de una nueva colonia de formación profesional (o, como rezaba el título del mismo, «un centro de adaptación, capacitación y disponibilidad de mano de obra rural»). Este proyecto tenía inicialmente un coste estimado de 630.000 dólares — es decir, casi la mitad del presupuesto global - y el Comité pensaba contribuir con 200.000 dólares - poco menos de un tercio de la partida destinada a los cuatro proyectos — ${ }^{40}$.

40 Idem. 
Tanto en Ginebra como en Buenos Aires siguió la discusión en torno a su diseño, que se modificó varias veces. Así, el lugar previsto para su ubicación se alejó de Santa Fe y pasó a ser un territorio de 500 hectáreas cercano a Choele Choel, en la provincia de Río Negro ${ }^{41}$. Asimismo, se redujo el coste presupuestado a 521.900 dólares y se estipuló que Argentina aportaría 191.900 dólares, además de los terrenos —el gobierno también debería encargarse de preparar y comenzar los trabajos de construcción-; el monto restante, 321.000 dólares, sería sufragado por el CIME con dinero procedente de su fondo especial y con cuotas de Estados Unidos, Italia y España. Finalmente, el Consejo Agrario Nacional (CAN) y el Comité firmaron un acuerdo el 11 de octubre de 1960 (ratificado en la XII Reunión del Consejo del CIME), por el que tanto el gobierno como el organismo se comprometieron a llevar el proyecto a ejecución ${ }^{42}$. Con todo dispuesto, sin embargo, el inicio de los trabajos se pospuso una y otra vez hasta que, en 1962, alegándose problemas presupuestarios del CAN, el proyecto fue cancelado.

Tras el fracaso del proyecto piloto, se decidió volver la mirada hacia Melchor Romero, una colonia cuyos planes de ampliación nunca habían sido del todo abandonados, aunque sí dejados en suspenso repetidas veces. De hecho, durante los preparativos del malogrado proyecto de Santa Fe y Choele Choel, la colonia de La Plata había seguido estando presente en las conversaciones: «Se ha discutido una vez más el proyecto Melchor Romero en la Argentina, para el que se dispone de viviendas y vías de comunicación, pero no se tiene noticia de que se haya efectuado ningún progreso ${ }^{43}$. Esos progresos llegaron finalmente en 1962, cuando se cancelaron las obras de Choele Choel y la propuesta relativa a Melchor Romero volvió a ser examinada. El CIME se comprometió de nuevo a financiar parte del proyecto, ahora con 78.500 dólares, procedentes de las contribuciones de Estados Unidos, Italia, España y Holanda — un nuevo país interesado - En esta ocasión, a diferencia de la

41 Informe del director sobre la labor realizada durante el periodo enero-agosto de 1959, 14 de septiembre de 1959, BOIM, MC/356. Véase también la noticia "Destinó el CIME 220.000 dólares para la Argentina", La Prensa (Buenos Aires, 15 de mayo de 1960), Biblioteca Nacional de la República Argentina, Buenos Aires (BNRA), Fondo Centro de Estudios Nacionales, Inmigración.

42 Memoria del director sobre las actividades y las finanzas del Comité en 1960, 10 de marzo de 1961, BOIM, MC/450. Véase también "Centro de recepción, entrenamiento y colocación de trabajadores rurales inmigrantes en Choele Choel", Revista de la DNM, II/5 (Buenos Aires, 1960): 430-432.

43 "Nuevas perspectivas para la colonización agrícola en Argentina", Migraciones Internacionales, III/1-2 (Ginebra, 1965): 75. 


\section{Foto 1: GRUPo DE INMIGRANTES RURALES ESPAÑOLES DESTINADOS A Melchor Romero (1964)}

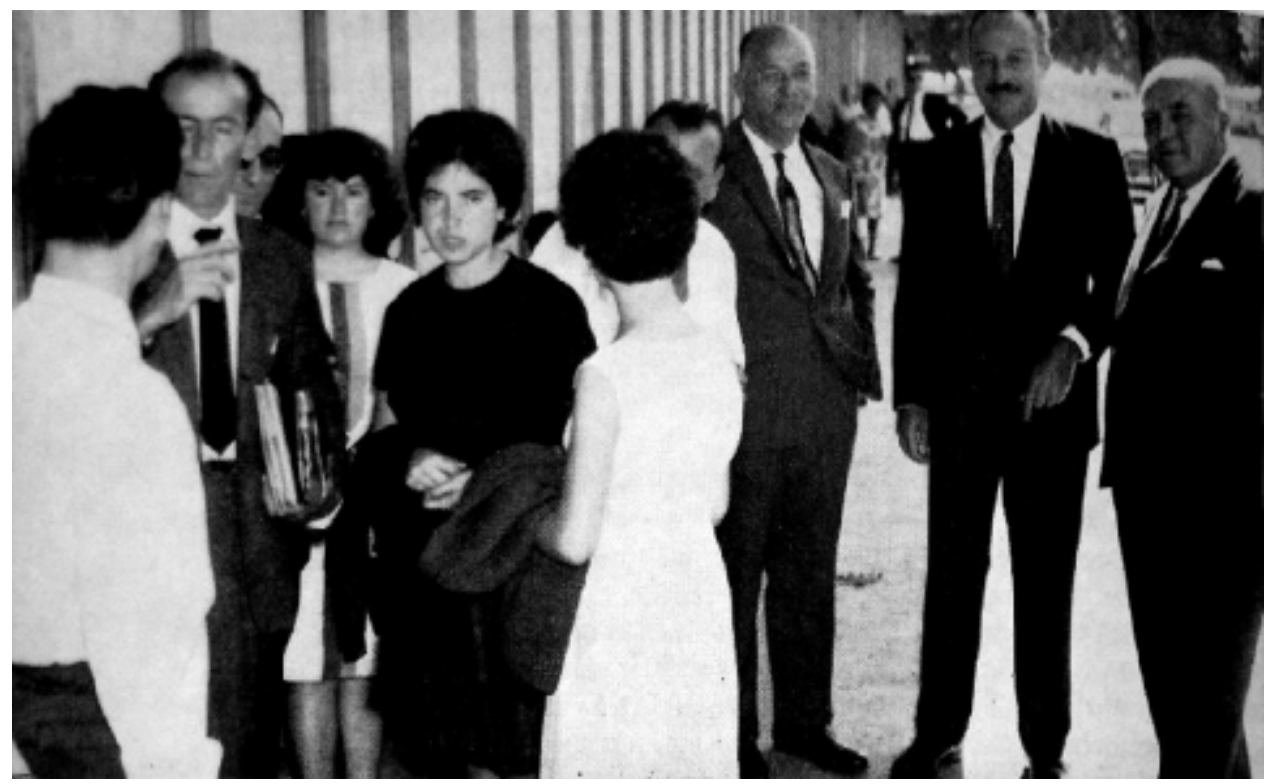

Detrás de ellos, Kenedi (jefe de la misión del CIME en Buenos Aires), Lillia (vicepresidente del CAN) y Dragonetti (gerente técnico del CAN). Fuente: "Nuevas perspectivas para la colonización agrícola en Argentina", Migraciones Internacionales, III/1-2 (Ginebra, 1965): 74.

anterior, el plan se llevó a ejecución y se lograron significativos avances, siquiera de manera efímera.

Las primeras cuatro familias, un total de veintiuna personas, llegaron a Melchor Romero procedentes de España en diciembre de 1964, ya durante el gobierno Arturo Umberto Illia. El procedimiento que antecedía a su llegada, a grandes rasgos, se ajustaba a las fases del resto de traslados llevados a cabo por el CIME. Las ofertas de trabajo eran enviadas a la misión del organismo en Madrid, donde expertos españoles entraban en contacto con las familias interesadas en radicarse en el campo argentino. Una vez examinados los candidatos y declarados aptos en un examen de selección profesional, se remitían sus expedientes a la misión del Comité del país de inmigración. Después de obtener el visto bueno, los interesados se sometían a un reconocimiento médico y llevaban a cabo la tramitación 
del visado, para finalmente emigrar a América con un contrato expedido a su nombre ${ }^{44}$.

Hacia 1966, diecinueve familias de origen español ya se habían establecido en las nuevas instalaciones de Melchor Romero. Este esperanzador comienzo quiso convertirse en un revulsivo para la colonización agrícola argentina. Así, aunque pronto surgirían los inevitables problemas que darían al traste con el proyecto, en un primer momento el CIME y el gobierno vieron abierto un prometedor horizonte:

El programa de inmigración de trabajadores rurales europeos que el CIME ha cumplido en Argentina en los últimos años era demostrativo de las posibilidades que se tenían de colocar a los inmigrantes calificados como colonos o aparceros en las explotaciones agrícolas existentes y que esta es una actividad que podía continuarse, con buenos resultados, en varias regiones del país ${ }^{45}$.

\section{EL FIN POSTERGADO DE LA INMIGRACIÓN COLONIZADORA}

Como acaba de verse, los inmigrantes de origen español se convirtieron en los primeros y principales contribuidores al éxito inicial de esta tardía colonización. Esto es coherente con la evolución de los flujos internacionales de la posguerra, a los que España se había incorporado tarde, permitiendo así que hacia 1961 el número de entradas en Argentina procedentes de España superase las cifras de la inmigración italiana, ya en franco declive. Dos años antes de esa fecha, en 1959, el director del Instituto Español de Emigración (IEE), Carlos María Rodríguez de Valcárcel, había mostrado su conformidad - al menos frente al CIME - con la marcha de trabajadores agrícolas españoles hacia el campo argentino, cuando en una reunión del Consejo afirmó que «en América Latina hay todavía una inmensidad de tierras sin explotar» y que «España puede contribuir a poblarlas» ${ }^{46}$.

El convenio migratorio firmado al año siguiente entre ambos países no hizo sino confirmar esa aquiescencia del gobierno español, que en el artículo 19 reafirmaba «su propósito de desarrollar planes de colonización agropecuaria en la República Argentina con la participación de inmigrantes españo-

44 Mulet, G. L., "El SAE en España”, Primer Curso Hispano Americano sobre Emigración, Madrid, BOIM, septiembre/octubre de 1963: 3-4.

45 "Nuevas perspectivas para la colonización agrícola en Argentina", Migraciones Internacionales, III/1-2 (Ginebra, 1965): 73-77.

46 Acta resumida de la $87 .{ }^{a}$ Sesión (X Reunión), 11 de abril de 1959, BOIM, MC/C/SR/87. 
les» ${ }^{47}$. De hecho, durante los años siguientes, los españoles construyeron el contingente más numeroso que participó de los proyectos de colonización argentina, por encima de italianos, holandeses e inmigrantes de otras nacionalidades, a pesar de que, considerada en el largo plazo, la proporción de trabajadores agrícolas sobre el total del flujo migratorio español había descendido notablemente en favor de trabajadores industriales y del sector servicios ${ }^{48}$.

\section{Foto 2: INMigrantes RURALES ESPAÑOles LABRANDO EN MELCHOR RoMero} (1964)

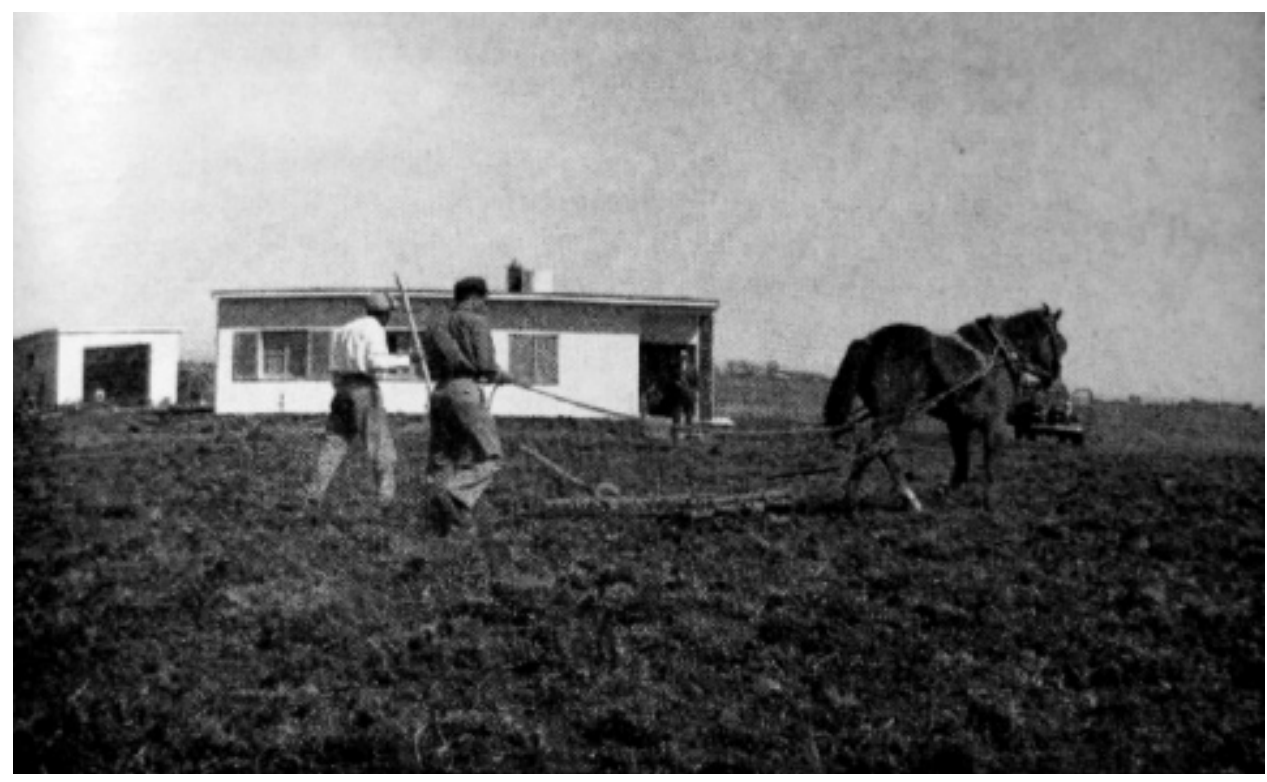

Fuente: "Nuevas perspectivas para la colonización agrícola en Argentina", Migraciones Internacionales, III/1-2 (Ginebra, 1965): 75.

47 Convenio de Migración entre España y la República Argentina, artículo 19, BOE, 187 (5 de agosto de 1960): 10990-10992. Véase también "Firma de un convenio de migración", $A B C$ (9 de julio de 1960): 31.

48 El grupo de trabajadores inmigrantes cuya actividad declarada estaba relacionada con el campo era aún numeroso, según se ha mostrado en el apartado anterior. Sin embargo, a pesar de las optimistas previsiones, también había quienes observaban su patente declive respecto a épocas pasadas: «Tradicionalmente, el emigrado español era trabajador agrícola. En los primeros años del siglo el porcentaje de emigrados del campo suponía más del 50 por ciento de la total emigración. Considerando el período 1946-1957, el porcentaje ha descendido ligeramente llegando a representar solamente un 16 por ciento». Isbert y Plaza, 1960, ap. Natale, 1963: 230. 
Una muestra más de la importancia que volvió a adquirir la migración rural española durante el cambio de década fue el interés en la misma mostrado, no ya por el Estado, sino también por las cooperativas privadas ${ }^{49}$. Aunque la relevancia de estas sociedades en el ámbito de la colonización no había sido seriamente considerada por el CIME en sus comienzos, pronto personas con un fuerte ascendiente dentro del Comité llamaron la atención sobre la necesidad de incluirlas en los planes. El estadounidense Francis E. Walter fue más allá al afirmar que «la planificación y administración de determinados proyectos de colonización tanto con colonos europeos como aborígenes debe encargarse preferentemente a compañías semioficiales y privadas registradas de acuerdo con la legislación de los países en los que tiene lugar la colonización y en los cuales las diferentes fuentes de capital y de crédito están representadas proporcionalmente de manera adecuada» ${ }^{50}$. Aunque no fue algo tan frecuente como el representante norteamericano hubiese deseado ni tan común como en épocas pasadas, estas cooperativas trataron en cualquier caso de jugar sus cartas.

Cabe mencionar, a modo de ejemplo, el caso de la Sociedad Colonizadora del Norte Argentino, más conocida por su acrónimo SOCONAR. Su administrador era Felipe Bonoli, quien había sido el responsable de la fundación en 1924 de Villa Regina, a la postre una próspera ciudad al pie de la meseta patagónica. Procedente de Italia, el ingeniero había destacado durante el período de la inmigración masiva por llevar a cabo, de manera exitosa, importantes proyectos de colonización en el Alto Valle del Río Negro ${ }^{51}$. Tras pasar unos años fuera del país - trabajando en proyectos similares en Perú, Bolivia

49 Como recuerda Lázzaro, «para el desarrollismo [argentino] la fortaleza de la expansión se asienta en la gran empresa privada, aunque el Estado no ha de asumir una posición neutral; debe promover el desarrollo, favoreciendo la capitalización privada en los sectores considerados clave». Lázzaro, 2012: 158.

50 Alocución pronunciada por el Sr. Diputado Francis E. Walter en la tribuna de la Cámara de los Representantes de los Estados Unidos de América, 9 de julio de 1956, BOIM, MC/INF/36. Francis E. Walter (1984-1963) fue miembro de la Cámara de Representantes de Estados Unidos por Pennsylvania. Destaca también su participación en el Comité de Actividades Antiestadounidenses, del que fue miembro entre 1951 y 1963. "Walter, Francis Eugene", History, Art \& Archives, U.S. House of Representatives: http://history.house.gov/People/Detail/2334.

51 Felipe Bonoli (1883-1967) llegó a Argentina en 1908, procedente de Italia, para trabajar con César Cipolleti, ingeniero responsable de algunas de las mayores infraestructuras relacionadas con la colonización a finales del siglo XIX. Bonoli destacó también por la constitución de la Compañía Italo-Argentina de Colonización, que fue la responsable de la fundación de la citada colonia - y ahora ciudad - de Villa Regina, en el Alto Valle del Río Negro. Petriella, 1976: 280. 
y Colombia - Bonoli volvió a la Argentina alentado por sus éxitos anteriores $\mathrm{y}$, en sus propias palabras, «resuelto a crear una corriente inmigratoria de Europa y particularmente de Italia y España a las provincias de Salta y Jujuy». Con este objetivo, se puso en contacto con Antonio Lago Carballo, subdirector de la oficina del CIME en España, y con el embajador argentino en Madrid, Héctor D'Andrea. Su intención última era la de conseguir familias de agricultores procedentes de la provincia de Murcia, para trabajar durante el invierno en el norte argentino en la producción de verduras que serían destinadas a los grandes mercados de consumo del litoral. En los casos precedentes, decía tratando de seducir a sus interlocutores, este tipo de cultivo había proporcionado a los colonos (españoles, en su mayoría) auténticas fortunas. «Se trata, por lo tanto, de una iniciativa interesante y que puede beneficiar a esas provincias, incorporando nuevos elementos de trabajo, que tanto lo necesi$\tan \rangle^{52}$.

Sin embargo, los tiempos habían cambiado. Las circunstancias de 1960 eran muy diferentes a las de 1924, y, por muy pujante que se mostrara la corriente migratoria española, distaba mucho de tener la entidad que en otros tiempos había permitido el desarrollo de proyectos colonizadores exitosos a largo plazo. Las mismas cifras de la inmigración española que provocaban esperanza en el gobierno, las sociedades privadas y el CIME, no eran sino los últimos coletazos de un proceso que llegaba a su fin. Incluso en el caso de Melchor Romero, donde hacia mediados de la década se había producido una destacable afluencia de agricultores españoles, pronto harían aparición los síntomas de su inviabilidad.

En 1969, tan solo tres años después de que la instalación de diecinueve familias en el complejo hubiese alentado los planes colonizadores del gobierno y el Comité, un memorándum del jefe de la oficina del organismo en España anunciaba que, en poco más de un año, habían sido repatriadas nada menos que trece familias (57 personas en total). En su intento de indagar en los motivos de este retorno masivo, el informe admitía que en alguno de los casos habían existido razones de «fuerza mayor, como enfermedad de un miembro de la familia», pero atribuía la mayor parte de la culpa a la negligencia y el capricho de los inmigrantes y sus contratantes. Así, mencionaba las siguientes causas: (1) «ofertas de colocación poco atractivas o de condiciones teóricamente aceptables y luego incumplidas por parte de los empleadores»; (2) «escasa o nula capacidad de algunos emigrantes para superar las

52 Carta de Felipe Bonoli al embajador Héctor D'Andrea, Buenos Aires, 2 de marzo de 1960, Archivo del Ministerio de Relaciones Exteriores y Culto, Buenos Aires (AMREC), Embajada de Madrid II, AH0028/2. 


\section{Foto 3: Inmigrantes eSPaÑoles en Melchor Romero (1965)}

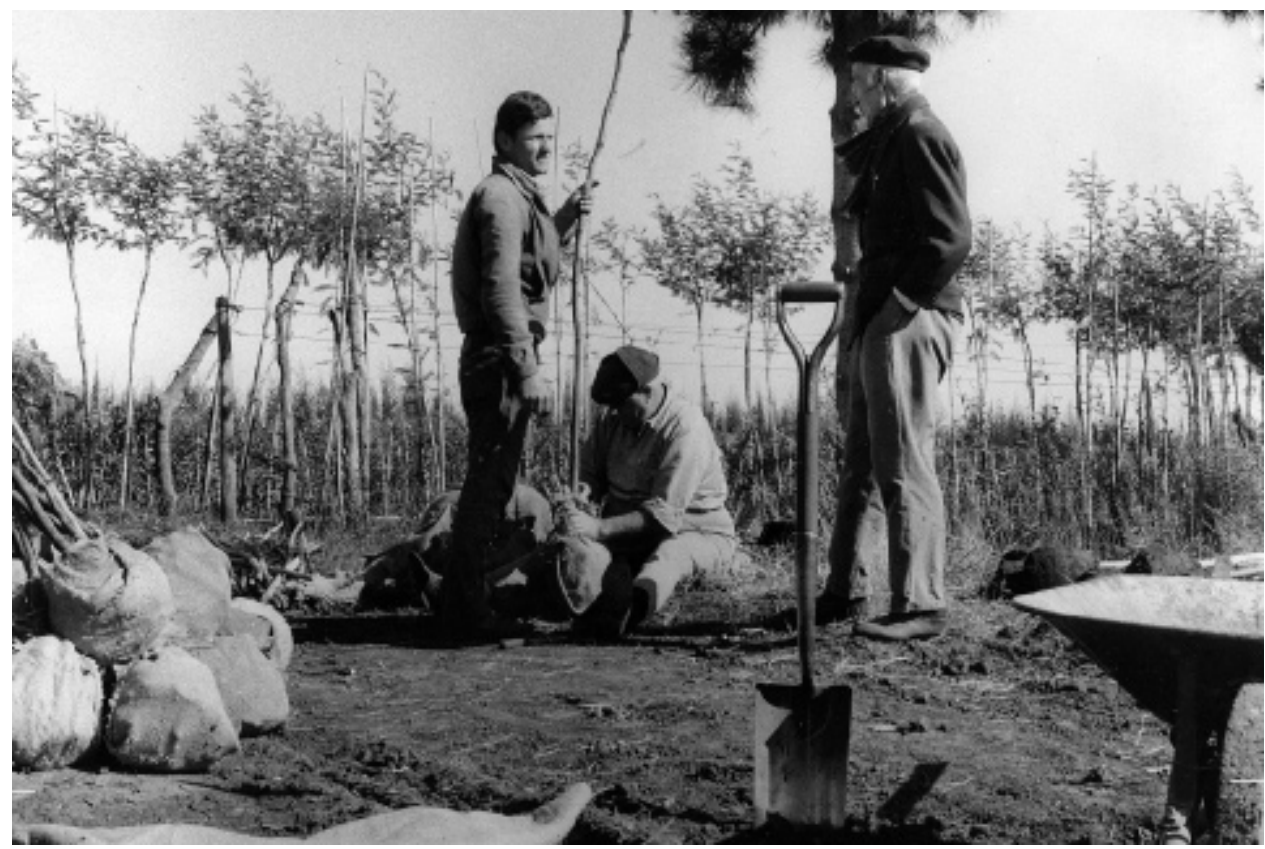

Fuente: IOM Media Library/Paul Almasy.

naturales dificultades de ambientación al medio rural argentino, dado que los reclutamientos solo pueden hacerse entre personas de bajo nivel cultural»; (3) «escaso o nulo interés por parte de la gran mayoría de los empleadores locales para facilitar dicha adaptación al medio ambiente» ${ }^{53}$. Sin embargo, el autor del informe omitía cualquier alusión a los obstáculos que los inmigrantes encontraban en su búsqueda de asistencia técnica o en el acceso al crédito bancario. En lugar de asumir alguna responsabilidad por las excesivas tasas de retorno, el CIME señalaba a los empleadores y, en especial, a los colonos, a quienes acusaba de una deficiente formación y una reducida capacidad de adaptación.

En resumen, en nuestra opinión, basada en la experiencia de cuatro años del Programa, ni las opiniones del seleccionador, ni las de los vecinos o conocidos del candidato, ni las del médico, podrán nunca garantizar la existencia en el candidato

53 Carta de Gaspar Gómez de la Serna al director del CIME, 6 de marzo de 1969, BOIM, Argentina, Melchor Romero (DPS-02-022). 
de aquellas cualidades personales básicas para lograr el éxito en un país extranjero. Por otra parte, las consecuencias de lo anterior son: actitudes individuales de «engañados», absurdas pretensiones salariales y de toda clase, acusaciones al CIME, molestias y amenazas a la Misión de Buenos Aires y, por último, peticiones de repatriación consular. Una vez en España, los repatriados vuelven a manifestar en términos a veces muy violentos y amenazadores, como el caso muy reciente de Ibáñez Molinero, sus resentimientos contra el CIME, considerando a nuestro Organismo culpable de su fracaso y retorno ${ }^{54}$.

En realidad, el desdén mostrado por el Comité hacia los inmigrantes en su diagnóstico del problema (algo infrecuente en la documentación consultada, dicho sea de paso) ha de ser interpretado como síntoma de la frustración y el abatimiento del organismo ante el enésimo revés que, hacia finales de la década de los sesenta, experimentaba en su intento de perpetuar una corriente migratoria estable desde Europa hacia América Latina. El análisis parecía olvidar la verdadera causa del problema, que no era otra que la progresiva pérdida de interés de los europeos por emigrar a ultramar. Pero, aunque la carta del jefe de misión en España no lo mencionara, el CIME no ignoraba las condiciones adversas en las que su labor se desenvolvía, ni desconocía las motivaciones de los trabajadores para emigrar. Diez años antes, el director ya había realizado una completa y acertada valoración de las razones que impulsaban a los migrantes a salir de su país nativo, y tenía en cuenta que la progresiva inversión de los factores sociales y económicos a uno y otro lado del Atlántico desalentaban el proceso ${ }^{55}$.

El CIME, por tanto, era consciente de que existían circunstancias que jugaban en contra de la emigración europea hacia los países latinoamericanos. $\mathrm{Y}$, sin embargo, parecía ignorarlas, al achacar a los migrantes el fracaso de unos planes cuya viabilidad era objetada por una realidad estructural desfavorable. En el fondo, subyacía la cuestión de que la causa originaria del CIME, la superpoblación europea, había desaparecido. En la búsqueda de nuevos objetivos para justificar su existencia, el organismo decidió centrarse en las necesidades de los países latinoamericanos, pero este enfoque contaba con el inconveniente de que seguía basándose en la misma tendencia migratoria obsoleta: la emigración europea hacia otros continentes. Así, el Comité quiso contribuir con su actividad al desarrollo económico y social de América Latina y, en ese afán, cerró el foco sobre la colonización rural —alentado

54 Ibidem. Solo unos años antes, los inmigrantes italianos - a los que los españoles habían sucedido como los más numerosos - se habían enfrentado a problemas muy similares. Véase Scarzanella, 2015: 127.

55 Política y programas para el año 1960, 8 de abril de 1959, BOIM, MC/343. 
tanto por los propios gobiernos implicados como por la administración estadounidense, dispuesta a paliar la conflictividad social en el medio agrario para frenar la propagación del comunismo-. Pero, como acaba de decirse, el problema era que en Europa no existía una demanda capaz de sostener tales aspiraciones. En lo concerniente a Argentina, podría concluirse, retomando lo que se apuntó al comienzo, que el mito de la colonización con inmigrantes siguió vivo en los planes gubernamentales hasta bien entrada la segunda mitad de siglo; pero que, dado lo anacrónico de su formulación y sus efímeros resultados, fue poco más que eso: un mito.

\section{BiBLIOGRAFÍA}

Aroskind, Ricardo, "El país del desarrollo posible", Daniel James (dir.), Nueva Historia Argentina: Violencia, Proscripción y Autoritarismo (1955-1976), Buenos Aires, Sudamericana, 2007: 63-116.

Barbero, M. Inés y Cacopardo, M. Cristina, "La inmigración europea a la Argentina en la segunda posguerra: viejos mitos y nuevas condiciones", Estudios Migratorios Latinoamericanos, 6/19 (Buenos Aires, 1991): 291-321.

Bastos de Ávila, Fernando, La inmigración en América Latina, Washington, D.C., Unión Panamericana, 1964.

Cerra, Ángel, "Las raíces ideológicas del desarrollismo argentino: La originalidad de Rogelio Frigerio", Técnica Administrativa, 9/4 (Buenos Aires, 2010): 1666-1680.

De la Peña, Guillermo, "Las movilizaciones rurales en América Latina desde c. 1920", Leslie Bethell (ed.), Historia de América Latina, vol. 12: Política y sociedad desde 1930, Barcelona, Crítica, 1997: 193-280.

Dos Santos, Theotonio, De la dependencia al sistema mundial. Balance y perspectivas, México D.F., UNAM, 1999.

Echavarría, José M., Filosofia, educación y desarrollo, México D.F., Siglo XXI, 1967.

Fernández, Alejandro, "La inmigración y las políticas de colonización avanzada en la Argentina (1910-1940)”, Elda González Martínez y Alejandro Fernández (eds.), Migraciones internacionales, actores sociales y Estados. Perspectivas del análisis histórico, Madrid, Iberoamericana/Vervuert, 2014: 13-36.

Frondizi, Arturo, Qué es el movimiento de integración y desarrollo, Buenos Aires, Sudamericana, 1983.

García Bossio, Horacio, "Desarrollismo cepalino vs desarrollismo frigerista: La Junta de Planificación Económica de la Provincia de Buenos Aires en la experiencia 
argentina (1958-1962)", Temas de Historia Argentina y Americana, 21 (Buenos Aires, 2013): 15-37.

Lázzaro, Silvia B., "Estado, desarrollo y reforma agraria en la provincia de Buenos Aires (1958-1962)", Anuario del Centro de Estudios Históricos "Prof. Carlos S. A. Segreti”, 8/8 (Córdoba, Argentina, 2008): 85-106.

Lázzaro, Silvia B., "El desarrollismo y el problema agrario durante las décadas de 1950 y 1960”, Secuencia, 84 (México D.F., 2012): 127-160.

Natale, Óscar, Aspectos jurídicos, económicos y sociales de la colonización con inmigrantes, Buenos Aires, Consejo Federal de Inversiones, 1963.

Papademetriou, Demetrios G. y Martin, Philip L. (eds.), The unsettled relationship: Labor migration and economic development, Connecticut, Greenwood Press, 1991.

Petriella, Dionisio, Los italianos en la historia de la cultura argentina, Buenos Aires, Asociación Dante Alighieri, 1976.

Pollock, David, Kerner, Daniel y Love, Joseph L., "Entrevista inédita a Prébisch: Logros y deficiencias de la CEPAL", Revista de la CEPAL, 75 (Santiago de Chile, 2001): 9-23.

Prébisch, Raúl, El desarrollo económico de la América Latina y algunos de sus principales problemas, Santiago de Chile, CEPAL, 1949.

Prébisch, Raúl, "Las cinco etapas de mi pensamiento sobre el desarrollo", Raúl Prébisch: Un aporte al estudio de su pensamiento, Santiago de Chile, CEPAL, 1987.

Quijada Mauriño, Mónica, "España y Argentina durante la segunda guerra mundial", Espacio, Tiempo y Forma. Serie V, Historia Contemporánea, 7 (Madrid, 1994): 231-257.

Redondo Carrero, Emilio, Migrantes y refugiados en la posguerra mundial. La corriente ordenada de españoles hacia Argentina, 1946-1962, Madrid, Sílex, 2017.

Rodríguez, Octavio, La teoría del subdesarrollo de la CEPAL, México D.F., Siglo XXI, 1993.

Scarzanella, Eugenia, "La última frontera: Notas sobre el Comité intergubernamental para las migraciones europeas y la colonización agrícola italiana en América Latina (1949-1964)", Elda González Martínez y Ricardo González Leandri (eds.), Migraciones transatlánticas: Desplazamientos, etnicidad y políticas, Madrid, Catarata, 2015: 112-133.

Senkman, Leonardo, "Política internacional e inmigración europea en la Argentina de post-guerra (1945-1948). El caso de los refugiados", Estudios Migratorios Latinoamericanos, 1 (Buenos Aires, 1985): 107-126.

Sunkel, Osvaldo (comp.), El desarrollo desde dentro: Un enfoque neoestructuralista para la América Latina, México D.F., Fondo de Cultura Económica, 1991. 
Szusterman, Celia, Frondizi and the politics of developmentalism in Argentina, 1955 62, Londres, MacMillan Press, 1993.

Fecha de recepción: 15 de mayo de 2015.

Fecha de aceptación: 30 de septiembre de 2015.

\section{Rural colonization with immigrants in mid-twentieth century Argentina: an ephemeral developmental drive promoted by ICEM}

Rural colonization with immigrants in Argentina is often considered a phenomenon confined to the late nineteenth and early twentieth centuries. By contrast, the later decades of the fifties and sixties are considered the era of industrialization. The objective of this article is to determine the extent to which this immigrant colonization was present in the Argentine government's plans in the middle of the century, to place these projects in an international context dominated by the developmentalist ideology, and to analyse the practical results of cooperation on the issue with the Intergovernmental Committee for European Migration (ICEM). To do so, I use mainly primary sources (including official correspondence, reports and proceedings) from the Argentine administration and the aforementioned Committee, as well as press articles and quantitative information.

KEY wORDS: Argentina; twentieth century; developmentalism; rural colonization; immigration; ICEM. 